\title{
Explaining Perceptions of Climate Change in the US*
}

\author{
Chiara Binelli†, Matthew Loveless ${ }^{\ddagger}$ and Brian Schaffner ${ }^{\S}$
}

This draft: 26 April 2020.

\begin{abstract}
Despite extensive scientific evidence, a significant proportion of the US population does not believe that climate change is a serious problem and immediate action is necessary. We merge individual-level data on climate change perceptions and the main determinants previously identified by the literature with county-level data on an exogenous measure of local climate change. Doing so allows us, for the first time, to test whether individuals' actual experience with long-trend changes in their local climate can override the power of partisanship that appears to have captured this opinion process. We find that partisanship and political ideology have the strongest effect on climate change perceptions, more so than long-run changes in local climate. We then run a randomized online experiment to test whether partisanship also drives the willingness to take action to combat climate change and individual environmental-friendly choices as much as it drives perceptions.

Key Words: Perceptions of Climate Change, Partisanship, Public Opinion, United States.
\end{abstract}

\footnotetext{
*We are very grateful to the authors of the 2017 PNAS paper "Spatial heterogeneity of climate change as an experiential basis for skepticism" for sharing the county-level data on the climate change indexes. We thank Robert Kaufmann and participants to the 2019 EMCC-IV conference and to the Departmental seminar at the Economics Department of the University of Siena for helpful feedbacks and suggestions. All errors are ours.

${ }^{\dagger}$ Department of Economics University of Milano-Bicocca, Italy. Corresponding author. Email: chiara.binelli@gmail.com

${ }_{\ddagger}^{\ddagger}$ Department of Political and Social Sciences, University of Bologna, Italy.

$\S$ Department of Political Science and Tisch College, Tufts University, USA.
} 


\section{Introduction}

Despite overwhelming scientific evidence, a significant proportion of the US population does not acknowledge that global warming is happening (Howe et al. 2015). ${ }^{1}$ An extensive literature on US public opinion has shown that partisanship and, to some extent, political ideology are the primary explanations for these divergent perceptions (Egan and Mullin 2017). The mechanism of partisanship is explained in a two-fold manner by the complex scientific content of the climate change issue: one, citizens have little motivation to look for accurate evidence and two, the low personal stakes in an issue that often seems geographically and temporally distant. Thus many Americans acquiesce to partisan elites for information (Egan and Mullin 2012; 2017).

Intuitively, an effective means to form a correct assessment of how the climate is changing would be direct exposure to the reality of climate change. Mounting evidence shows that personal experience with the daily weather is more effective than statistical information provided by experts because it is more vivid and accessible. Perceived changes in local temperature have been linked causally to changes in global warming beliefs, an effect termed local warming (Zaval et al. 2014).

Yet, climate change differs from weather change as it refers to changing weather patterns over a long period of time. Faced with the difficulty of measuring how individuals experience climate change, the literature has taken one of two approaches: measuring changes in the climate with changes in the weather (e.g. Egan and Mullin 2012) or exploiting exposure to extreme weather events (such as excessive heat, droughts, flooding, and hurricanes) that could have a direct impact on climate change perceptions (Konisky et al. 2016). Both approaches have found evidence of a positive relationship between weather changes and expressions of concern about climate change. However, the effects are both modest and short-lived. Overall, the evidence that weather shapes climate change opinions is mixed because of the heterogeneity of the study populations, weak causal identification strategies and research designs (Howe et al. 2019).

\footnotetext{
${ }^{1}$ We use climate change and global warming interchangeably, although the former technically refers to all forms of climatic variability introduced by the warming of the Earth's surface and oceans due to the increased accumulation of greenhouse gases in the Earth's atmosphere (see National Research Council. 2001. Climate Change Science. Washington, DC: National Academy Press.).
} 
Using poor heuristics - by proxying changes in the climate with changes in the weather - limits our ability to answer the following questions: Can the direct experience of climate change can have a causal impact on individuals' climate change perceptions? Can this direct experience compete with and even mitigate the effect of partisanship on individuals' climate change perceptions? How do these competing explanations drive support for environmental policy actions and individual environmental-friendly choices? The answer to the last question is crucial to define an effective strategy to reduce emissions and shape the debate on climate change. Finding that partisanship has a dminished effect on subsequent behavioral choices would open the possibility of promoting important behavioral changes to combat climate change.

Due to increased data availability, several papers have proposed improved measures of climate change by using long-term temperature trends (Howe et al. 2019 for a review). On example is Kaufmann et al. (2017) that propose a methodology to measure local climate change in the US based on a county-level index of the number of days per year for which the year of the record high temperature is more recent than the year of the record low temperature in the last thirty, forty and fifty years. The index is an accurate measure of county-level long-run changes in the climate, it is exogenous to individuals' choices and location, and thus allows the identification of the causal impact of experiencing climate change on perceptions of this reality. Exploiting this opportunity, we develop a two-stage empirical analysis. First, we merge the county-level index of climate change with detailed individual-level data from the 2014 Cooperative Congressional Election Study (CCES) to estimate a model of climate change perceptions that controls for the climate change index in the county of residence and all relevant determinants of climate change perceptions identified by the previous literature. While we identify significant effects of locally experiencing climate change on perpcetions, we find that partisanship and political ideology have the strongest effect, more so than longrun actual changes in local climate: being Republican and conservative is associated with a significant reduction in acknowledging the reality of climate change and the urgency to take action. Second, we run a randomized online experiment to test whether the willingness to take action to combat climate change and individual environmental-friendly choices (such as the installation of solar panels and the use of hybrid and electric cars) are driven by 
partisanship as much as perceptions of climate change are. Finding that policy support and individual actions were less or not at all driven by partisanship would provide an important finding to promote active changes to reduce emissions. Taken together, this evidence has the potential to define both the dimensions and the nature of the political challenge needed to combat climate change.

The remainder of the paper is as follows. Section 2 briefly discusses the previous literature, Section 3 describes the data, Section 4 presents the main model, Section 5 discusses the results, and Section 6 presents some robustness checks. Section 7 discusses the experiment, and Section 8 briefly concludes. The Appendix reports all tables and figures.

\section{Literature Review}

Our work speaks to the public opinion literature on the determinants of individuals' climate change perceptions in the US. Egan and Mullin (2017) review the literature and identify the following five main groups of determinants, in order of importance: political preferences (partisanship and political ideology), demographics, particularly gender and religiosity, personal experience with climate change, worldviews on social relationships (e.g. hierarchical versus egalitarian orientation), and media. Overall, several papers have shown that partisanship and political ideology drive Americans' opinions on the existence of global warming more than any other factor, including personal experience with and vulnerability to changes in the weather (Egan and Mullin 2017).

Yet, one significant limitation of the literature is the measurement of individuals' experience with climate change, most commonly proxied with various measures of personal experience with changes in the weather. Specifically, climate heuristics are calculated by comparing the temperature during a given day (Zaval et al. 2014; Brooks et al. 2014), week (Egan and Mullin 2012), season (Akerlof et al. 2013; Howe and Leiseowitz 2013), or year (Goebbert et al. 2012; Howe et al. 2013) with a long-run average for the corresponding period and classifying this anomaly as either warmer or cooler than average. However, weather changes and climate change are different: the daily, weekly, seasonal, or annual deviations from the mean do not represent a change in climate. Climate change is a shift in the long-run 
weather means. Thus, the use of weather measures to proxy individuals' experience with climate change in models of attitudes toward climate change could potentially introduce a substantial source of bias.

Recent developments in big data collection and analysis have produced exponentially improved measures of individuals' experience with climate change. Due to increased data availability, several papers have proposed improved measures of local climate change by using long-term temperature trends (Howe et al. 2019 for a review). One example is Kaufmann et al. (2017) that have developed a county-level index of the number of days per year for which the year of the record high temperature is more recent than the year of the record low temperature in the last thirty, forty and fifty years. The index also allows for a differential impact of more recent and extreme changes in temperature to capture two key aspects that influence perceptions of climate change: recency weighting and an emphasis on extreme weather events.

Kaufmann et al. (2017) show a significant correlation between the cross-county variation in the index and changes in the proportion of the US population that agree that global warming is happening. They also show that recency weighting is key in that recent record temperatures have a particularly strong effect on beliefs and climate skepticism is greater in counties exhibiting recent cooling versus counties that have warmed. However, Howe et al. (2019) review the literature on climate change perceptions and find that there are mixed findings among studies that have investigated the impact of longer-term temperatures or temperature trends on climate change perceptions using aggregate data. Empirical analysis at an aggregate level can only present correlations between geographical variation in climate change and the degree of public opinion awareness across geographical units. Since weather varies geographically, geographic patterns of a particular weather variable may coincide with the geographic patterns of other unmeasured social, cultural, political, or demographic predictors. This means that meteorological variables may be correlated with other latent phenomena that are also causal drivers of the dependent variable.

In order to assess the impact of experiencing climate change on climate opinion it is necessary to perform individual-level analysis. In this paper we do so by estimating an individual-level model of climate change perceptions that controls for the climate index 
developed by Kaufmann et al. (2017) together with the relevant determinants of climate change beliefs identified in the literature (Egan and Mullin 2017).

\section{Data}

The 2014 CCES is the second wave of the 2012 CCES administered online by YouGov. YouGov uses a matched random sample design which involves first selecting a random sample from the target population (American adults) from the Census Bureau's American Community Survey and then identifying the closest matching respondents from their own panel on a range of demographic factors. This creates a representative sample of the target population and post-stratification weights are used to ensure that the resulting sample was representative of American adults on a wide array of demographic and political characteristics. The survey was conducted in two waves, with respondents interviewed in October (before the election) and again in November and December (following the election). All variables used in our analyses come from the pre-election wave of the survey. ${ }^{2}$

The CCES includes detailed information on socio-demographic characteristics, values and attitudes, partisanship and political ideology, which allow controlling for the main determinants of climate change perceptions previously identified by the literature. Importantly, the CCES also includes a robust question on climate change perceptions that use neutral wording and combine the recognition of the problem with the willingness to promote active policy action. The question is as follows: "From what you know about global climate change or global warming, which one of the following statements comes closest to your opinion? a. Global climate change has been established as a serious problem, and immediate action is necessary; b. There is enough evidence that climate change is taking place and some action should be taken; c. We don't know enough about global climate change, and more research is necessary before we take any actions; d. Concern about global climate change is exaggerated. No action is necessary; e. Global climate change is not occurring; this is not a real issue." We reverse coded the question so that an increasing value of the dependent variable

\footnotetext{
${ }^{2}$ The guide to the 2012 CCES provides detailed information on the methodology (Ansolabehere and Schaffner 2013).
} 
denotes acknowledgement that climate change is happening.

Using the information on the individuals' county of residence (i.e. FIPS county codes), we merge the 2014 wave of the CCES dataset with the county-level data on the climate indexes constructed by Kaufmann et al. (2017). The climate indexes are constructed using data on the daily high and low temperatures for 18,713 weather stations located in the US. Kaufmann et al. (2017) classify each station according to the number of years for which data are available and the number of observations that are missing, and consider stations with a maximum number of 5, 10 and 15 missing observations. For each station, they construct an index, the TMax, which is calculated as the number of days the record high temperature is more recent than the record low temperature over a period of thirty, forty and fifty years. The latest record is 2014, so the sample runs up to 2014 using all data records for the 30, 40 and 50 previous years. ${ }^{3}$ This process is repeated for each day of the year, and the values of zero or one are summed over to calculate the index. All portions of US counties are assigned to their nearest weather station. The station-level values of the index are translated to county-level values of the index using a weighted average that is based on the US voting population.

Kaufmann et al. (2017) identify four relevant intervals of the TMax that characterize the long-run time trends in changes in temperature in each county: strong cooling (TMax $₹$ 163), cooling (163 < TMax $₹ 182)$, warming $(182<$ TMax $\leqslant 201)$, and strong warming (TMax > 201). Finally, in addition to the TMax, they define High2005 and Low2005, which denote, respectively, recent warming and recent cooling since 2005. In particular, High2005 measures the number of days per year for which the year of the highest temperature is more recent than the year of the lowest temperature and the year of that high temperature is 2005 or later. Reverse, recent cooling, Low2005, is computed as the number of days per year for which the year of the lowest temperature is more recent than the year of the highest temperature and the year of that low temperature is 2005 or later.

The additional indexes High2005 and Low2005 are used to capture "recency weighting" $(R W)$, that is the impact of recent changes in the climate, which could have a stronger

\footnotetext{
${ }^{3}$ To ensure that the index measures long-term changes in the weather, that is a change in the climate, the minimum sample length of temperature data is thirty years.
} 
impact than less recent changes and thus reinforce the effect of record temperatures (Weber and Stern 2011; Li, Johnson and Zaval 2011). In order to measure recency weighting, Kaufmann et al. (2017) construct four $R W$ variables, which are the interactions between recent warming (High2005) and recent cooling (Low2005) and the climate trends measured by the TMax. In particular, $R W 2(R W 1)$ is the interaction between High2005 and $163<$ TMax $₹ 182($ TMax $₹ 163)$ and measures the effect of recent warming in counties that experience sample-wide (strong) cooling. Reverse, $R W 3(R W 4)$ is the interaction between Low 2005 and $182<$ TMax $\leqslant 201$ (TMax > 201), and measures recent cooling in counties that experience sample-wide (strong) warming.

Table 1 presents the number of observations and counties for the four different intervals of the TMax index using the 30-years series. ${ }^{4}$ Table 1 shows that the vast majority of US counties have experienced sample-wide warming. In particular, 1,681 $(6,819)$ counties have (strongly) warmed, and only 685 (313) counties have (strongly) cooled. Tables 2, 3 and 4 present descriptive statistics of the CCES climate change perceptions' question, political ideology and partisanship. ${ }^{5}$ Figure 1 presents climate change perceptions by partisanship and clearly shows a strong correlation between being a Republican and not acknowledging that climate change is happening. ${ }^{6}$

\section{Model}

We follow Egan and Mullin (2002) and estimate a standard model of climate change perceptions:

\footnotetext{
${ }^{4}$ In Table 1, as in the main regressions, we use the TMax index constructed using the 30 years time trends. All results are robust to using the 40 and 50 years series.

${ }^{5}$ Descriptive statistics of the rest of the variables that will be used in the empirical analysis are available in the Online Appendix.

${ }^{6}$ Following the US public opinion literature, we use a self-identification measure of partisanship rather than party registration since we conceive of partisanship as an identity, thus the reported information is accurate because that is what the respondent told us they are.
} 


$$
\begin{aligned}
y_{i c}= & \beta_{0}+\beta_{1} \text { TMax }_{c}+\beta_{2} R W 1_{c}+\beta_{3} R W 2_{c}+\beta_{4} R W 3_{c}+\beta_{5} R W 4_{c}+ \\
& +\beta_{6} P_{i c}+\beta_{7} \operatorname{PolId}_{i c}+\gamma \mathbf{X}_{i c}+\alpha_{c}+\varepsilon_{i c}
\end{aligned}
$$

where $y_{i c}$ is the perceptions of climate change of individual $i$ in US county $c$. TMax and $R W j_{c}, j=1,2,3,4$ are, respectively, the TMax index and the four recency weighting effects in county c. $P I D_{i c}$ is party identification, $P o l I d_{i c}$ is political ideology, and $\mathbf{X}_{i c}$ is a vector of individual characteristics (gender, race, age, education, religiosity) of individual $i$ in county c. $\alpha_{c}$ is the county fixed effect, and $\varepsilon_{i c}$ is a normally distributed error term. We cluster the standard errors at the county-level and estimate the model using ordered probit.

In addition to the standard variables identified by the previous literature, equation 1 contains the five climate indexes that we described in Section 3: the TMax index, which measures local changes in the climate in each county $c$ based on the number of days per year for which the year of the record high temperature is more recent than the year of the record low temperature, and the four recency weighting $(R W)$ variables, which are interaction terms between recent warming and recent cooling temperature trends and the four relevant climate trends measured by the TMax.

Since the CCES suervey elicits perpcetions of climate change rather than perceptions of global warming, we expect all climate indexes' coefficients to be positive. In particular, we expect both an increasing warming trend as measured by higher values of the TMax, and directional changes in the climate with respect to the county's long run temperature trend to increase the propensity to agree that climate change is happening. Therefore, we would expect both $\beta_{1}$ and all the coefficients of the $R W$ variables $\left(\beta_{2}, \beta_{3}, \beta_{4}, \beta_{5}\right)$ to be positive: in counties that experience sample-wide warming, we would expect recent cooling to increase acknowledgement that climate is changing, and, reverse, in counties that experience samplewide cooling, we would expect recent warming to increase acknowledgement that climate is changing.

The model is fully parametric. However, it is useful to understand what helps identify the main effects of the climate indexes. The identification of the model exploits cross- 
counties' variation. In particular, county dummies control for the impact of permanent regional differences, which may confound the effect of the climate indexes on perceptions. Therefore, county dummies absorb permanent regional differences, which allow us to identify the effect of the climate indexes on perceptions from the way they change differentially across space. The key identifying assumption is that the climate indexes are exogenous to individuals' choices and location given counties' aggregate effects.

\section{$5 \quad$ Main Results}

Table 5 presents the estimation results of the baseline model. The TMax index has a positive and statistically significant impact on climate change perceptions, and the size of the effect is the biggest in the full model that includes all relevant determinants. We also find evidence

of important recency weighting: as expected, all variables have a positive effect, with the exception of recent cooling in counties that have strongly warmed. Sizewise, the biggest effect is due to recent warming in counties that have cooled, which impacts climate change perceptions 25 times the size of the impact of recent cooling in counties that have warmed. In order to compare the relative size of the impact of each variable included in equation 1 , we can compute the average marginal effects for each value of the dependent variable from baseline model 3. The results, in Figure 2 in the Online Appendix, show that while partisanship and political ideology have the biggest impact, for each value of the dependent variable, recent warming in counties that have cooled is the variable with the third biggest effect.

In order to interpret the impact of the TMax and the recency effects, we follow Kaufmann et al. (2017) and compute the response in the dependent variable if TMax was moved to its sample mean for every county, and, likewise, we quantify the impact of the recency variables by considering their effect on each county if the condition on the TMax index is satisfied (TMax < 163, TMax > 201, etc.). Table 6 presents the minimum and maximum statistically significant average marginal effect by value of the dependent variable for the TMax and the recency effects variables from Model 3 in Table 5. The effects are sizeable and in the expected direction: the individual effects of the recency weighting on climate change 
perceptions range from a minimum of $-1,96$ for outcome 1 ("Global climate change is not occurring; this is not a real issue") to a maximum of $+3,19$ percentage points for outcome 5 ("Global climate change has been established as a serious problem, and immediate action is necessary") across all counties; the average marginal effect of the TMax index ranges for a minimum of $-0,5$ for outcome 1 to a maximum of 0,82 percentage points for outcome 5 . Among the recency effects, strong recent warming in counties that have cooled has the largest positive effect on beliefs that climate change is a serious problem and immediate action is necessary. Figure 3 in the Online Appendix reports the four histograms presenting the full distribution of the TMax and the recency effects variables across all counties for outcome 5, "Global climate change has been established as a serious problem, and immediate action is necessary". 7

The baseline results show that partisanship and political ideology drive perceptions of climate change: being Republican and conservative is associated with a significant reduction in the ability to acknowledge the reality of climate change and the urgency to take action. The very conservative and the strong Republican are the least likely to respond correctly. The next question is: does locally experiencing climate change have heterogenous effects for Republicans and Democrats? In other words, do Republicans and Democrats differently experience the reality of climate change in their county of residence?

In order to answer this question we augment the model with interaction terms between TMax and partisanship and between TMax and political ideology. The results, in Table 7, show that the additional variables leave the main results unchanged and identify only one statistically significant negative interaction between being conservative and experiencing climate change so that for conservatives experiencing an increasing warming trend is associated with a reduced ability to recognize climate change. This finding is consistent with an emerging literature in social psychology that has found evidence of American conservatives having a "negativity bias" so that the nature of their psychological responses to features of the environment that are negative is stronger than for liberals (Hibbing et Al. 2014).

\footnotetext{
${ }^{7}$ Histograms for each of the other four values of the dependent variable are available from the authors.
} 


\section{Robustness Checks}

We run several robustness checks of the baseline model's results. First, we perform a series of statistical checks. In particular, we estimate the baseline model 3 using different maximum of missing values (5 and 15) for the TMax index, and different time trends for the temperature series (40 and 50 years). The results are presented in Tables 9 and 10 of the Online Appendix. The main results are unchanged and there is no substantive difference with respect to the baseline model's results. We also estimated the baseline model using an ordered logit and the results, available from the authors, are unchanged.

Second, we estimate a number of modified versions of the model. First, we control for the availability of information on relevant economic outcomes and macroeconomic conditions, which could be an important variable affecting climate change perceptions. In particular, we would expect that the more accurately an individual is able to assess relevant macroeconomic conditions, the more likely the individual correctly perceives reality, thus acknowledging the existence of climate change. The CCES data contain a question on the level and on the change of the unemployment rate. Assuming that the information on the unemployment rate proxies for information on relevant macroeconomic conditions, we use the deviation of the respondent's prediction from the actual value of the unemployment rate to proxy for relevant economic knowledge. In the CCES, individuals report both the unemployment rate in 2014, and its change in the last two years. According to the US Bureau of Labor Statistics, unemployment rate in October 2014 was $5.7 \% .^{8}$ In October 2012, the unemployment rate was $7.8 \%$, thus between 2012 and 2014 the unemployment rate decreased. While $84 \%$ correctly states that unemployment decreased, $75 \%$ overestimates its level in 2014 by rating it higher than $6 \%$. We use the level variable to construct an accuracy of unemployment rate variable as the ratio between the absolute difference between the prediction and the actual unemployment rate over the actual unemployment rate. As expected, the percentage inaccuracy in predicting unemployment rate is negative and significant, but it does not affect the sign and significance of the climate variables.

Second, we control for risk aversion, which could also affect perceptions of climate change

\footnotetext{
${ }^{8}$ http://www.ncsl.org/research/labor-and-employment/national-employment-monthly-update.aspx
} 
as a reality that involves a trade-off between the present and the future time. In particular, someone that is highly risk-taker may disregard climate change since her utility function highly discounts the future. We use a series of CCES question on an hypotetical lottery to construct a standard measure of risk aversion. We find that risk aversion is significant and, as expected, positive: the more an individual is risk averse, the higher the propensity to recognize the reality of climate change and the need to take immediate action. As it was the case for the availability of information's proxy, the inclusion of risk aversion does not change neither the sign nor the significance of the climate variables. ${ }^{9}$

Third, we recode the dependent variable as a three-categories variable as in Egan and Mullin (2012). In particular, we construct a new dependent variable that is equal to 1 if $y \leqslant 2$, it is equal to 2 if $y=3$, and it is equal to 3 if $y \geqslant 4$. The results, available from the authors, are unchanged. ${ }^{10}$

Finally, we change the estimation sample in two different ways. First, we estimate the model using the 2012 wave of the CCES dataset. We do so to address an important concern: the sample of respondents in the 2014 CCES wave is affected by attrition since only the sub-sample of those that are willing to participate to the survey again is included. The 2012 CCES wave has 52,632 observations, while the 2014 CCES sample size is less than a fifth of the 2012 sample size. Therefore, it is possible that the 2014 CCES sample might overrepresent the more politically interested and motivated. The results, which are available from the authors, fully confirm the model's robustness: all explanatory variables have the same sign and statistical significance as in the baseline model. ${ }^{11}$

\footnotetext{
${ }^{9}$ If we include both risk aversion and the variable on the accuracy of the unemployemt rate, we find the same results: both these two variables are statistically significant with the expected sign and there is no change in the sign and significance of the climate variables. We also control for interest in government and public affairs using a variable that asks to self-report how much time is spent on following what is going on in government and public affairs. The impact of this additional variable is not statistically significant and leaves the results unchanged.

${ }^{10} \mathrm{We}$ also tried to use as a dependent variable a direct question on support for environmental policy. The CCES asks a question on voting in favour or against the American Clean Energy and Security Act that imposes a cap on carbon emissions and allows companies to trade allowances of carbon emissions, and funds research on renewable energy. While in the overall sample, $54 \%$ is in favour of the Clean Energy and Securit Act, $81 \%$ of Republicans are against it. However, unfortunately, there are only 93 counties for which there is some within country variation of this variable. Therefore, the county dummies saturate the model.

${ }^{11}$ Since the climate indexes are constructed considering climate trends up to 2014, when we merge them with the 2012 CCES wave, we have to assume that the weather changes between 2012 and 2014 do not strongly affect the 30 years average, so that the index is a relevant explanatory variable for climate change
} 
Estimating the model for 2012 does also help addressing an additional concern. If people have changed partisanship between 2012 and 2014, there could be some unobservables that have simultaneously made someone change partisanship and affected his/her climate change perceptions. Finding no change when we estimate the results for 2012 is consistent with changes in partisanship not affecting the results. We can also measure the stability of party identification and political ideology using the panel data feature of the CCES. Between 2012 and 2014 the within-respondent correlation for party id is higher than 0.9.

Second, we estimate the model for the sample of those that have been resident in a given county for at least 30 years, that is for the sample of those that have been directly exposed to the 30 years series of changes in weather that we use to measure climate change. We expect those that have been continuously exposed to the relevant 30-years change in the climate trend in the county of residence to be the ones that react the most to individually experiencing climate changes. As expected, considering only those that have lived in the same country of residence for at least 30 years substantially reduces the sample, which decreases to a third of its original size. Due to the small sample, the TMax index and most recency weighting become statistically insignificant. However, we are able to identify an important climate effect and of the expected size compared to the overall sample: recent warming in counties that have cooled has a size effect that is more than five times as big as in the overall sample.

\section{Experiment}

The results in the previous sections show that experiencing climate change at the individual level has an important effect on climate change perceptions but does not override the power of partisanship and political ideology. We also fail to find any evidence of significant interaction effects between experiencing climate change and partisanship so that the ability of acknowledging the existence of climate change seems to be the result of a pure partisanship effect rather than the result of being more or less able to see climate change as a function of partisanship (for example because one party provides more accurate information than the perceptions in 2012. 
other). The importance of partisanship confirms the findings from the previous literature (Egan and Mullin 2017).

We now ask the following question: does partisanship drive support for environmental policy actions and individual environmental-friendly choices as much as it drives perceptions? The answer to this question is crucial to define an effective strategy to reduce emissions and shape the debate on climate change. Finding that policy support and individuals actions were less or not at all driven by partisanship would provide an important finding to promote active changes to reduce emissions. We address this question by running an online randomized experiment where we randomly prime information on local climate change and partisanship, and we assess the impact of this priming on individuals' perceptions of climate change as well as support for policies to fight climate change and willingness to engage in individual behavior that would address climate change.

Two recent studies are closely related to this work. In particular, Guilbeault, Becker, and Centola (2018) assess the impact of partisan priming on the ability to recognize climate change in structured bipartisan networks. They show that belief exchange on climate change in a bipartisan network can significantly improve the ability of both conservatives and liberals to interpret climate data, while social learning can be reduced and polarization maintained when the salience of partisanship is increased, either through exposure to the logos of political parties or through exposure to political identity markers.

Mildenberger, Howe and Miljanich (2019) combine satellite imagery and voter file data to examine the political identities of US households with residential solar installations. They find that while households with solar installations are slightly more likely to be Democratic than Republican, households with solar installations exist across the political spectrum, despite extreme ideological polarization around climate change. They also find that solar households are more politically active than adjacent non-solar households, and these differences in political participation are more substantial than cross-group differences in partisanship.

\subsection{Experiment's Design}

We start the experiment by randomly assigning the following four conditions to respondents using a random integer between 1 and 4: 
Control: no priming for partisanship, no priming for local effects of climate change.

Treatment 1: no priming for partisanship, prime local effects of climate change.

Treatment 2: prime partisanship, no priming for local effects of climate change.

Treatment 3: prime both partisanship and local effects of climate change.

We assess the effect of each of the three treatments on several outcome variables: perceptions of climate change, support for policy actions to fight climate change, and willingness to engage in behavior that would address climate change such as the installation of solar panels and the use of hybrid and electric cars.

We prime the local effects of climate change by using an interactive climate change map that asks for the respondents place of residence in the US and reports what the climate will most closely resemble in 60 years if emissions stayed at the high level they are currently at. Respondents are required to enter this information manually to show they have been shown these data. We prime partisanship by asking respondents to match the Republican or Democrat logos with the corresponding party. These logos are highly effective at priming partisan bias based both on party membership and political ideology (Guilbeault, Becker, and Centola 2018).

We run the experiment using subjects from Lucid that passes on demographics on subjects, so we have informaion on individuals' education, age, gender, race, income, and party identification without having to ask any question. In addition, we also ask a question on religiosity and a question on worldviews related to social relationships (whether everyone should have equal opportunities), which have been found to be associated with perceptions of climate change (Egan and Mullin 2017). In order to detect a difference of 0.33 points on the five-point scale with power of 0.9 , we include 300 individuals per condition for a total $N$ of 1,200 .

To begin our analyses, we measure baseline differences in all outcome variables (climate change perceptions, support for policy actions to fight climate change, and willingness to engage in behavior that would address climate change) between Republicans and Democrats. All subjects in round 1, regardless of experimental condition, provide an independent estimate of each outcome variable, so that, for this baseline measurement, all subjects constitute independent observations. 
Due to the covid-19 crisis, we have postponed fielding the experiment. The experiment is currently planned to be fielded in the fall of 2020 .

\section{Conclusion}

$46 \%$ of Americans do not support taking action to combat climate change and $61 \%$ disagree that climate change is mostly due to human activities (ANES 2016). Estimating a comprehensive model of climate change perceptions that control for an accurate measure of individuals' experience with local climate change, we find that experiencing climate change has important effects. Both locally experiencing a warming climate and recent inversions of the long-run weather trend in the county of residence increase the probability of acknowledging the reality of climate change and the urgency to take action. Recent warming in counties that have cooled has a particularly positive impact on climate change perceptions. In other words, experiencing a recent warming of the weather's trend in the county of residence increases the probability of agreeing that climate change is happening and immediate action is necessary.

However, individuals' personal experiences with climate change are not able to override the powerful tide of partisanship and political ideology that remain the main factors driving perceptions. Climate change perceptions appear to derive from parties - ostensibly as information providers - rather than from the objective reality of individual experiences with climate change. For conservatives, parties either provide wrong information or demand constituents to hold views on climate change that run counter to overwhelming scientific consensus (Intergovernmental Panel on Climate Change AR5). Finally, we run an online randomized experiment to test whether partisanship also drives the willingness to take action to combat climate change and individual environmental-friendly choices as much as it drives climate change perceptions. 


\section{References}

[1] Akerlof K, Maibach EW, Fitzgerald D, Cedeno AY, Neuman A. 2013. "Do people "personally experience" global warming, and if so how, and does it matter?" Glob Environ Change, 23(1):81-91.

[2] American National Election Studies, University of Michigan, and Stanford University. ANES 2016 Time Series Study. Ann Arbor, MI: Inter-university Consortium for Political and Social Research [distributor], 2017-09-19. https://doi.org/10.3886/ICPSR36824.v2

[3] Brooks JD, Oxley DR, Vedlitz A, Zahran S, Lindsey C. 2014. "Abnormal daily temperature and concern about climate change across the United States." Rev Policy Res, $31(3): 199-217$.

[4] Egan, Patrick J. and Megan Mullin. 2017. "Climate Change: US Public Opinion", Annual Review of Political Science, 20:209-227.

[5] Egan PJ, Mullin M. 2012. "Turning personal experience into political attitudes: the effect of local weather on Americans' perceptions about global warming." J. Polit., 74:796-809.

[6] Goebbert K, Jenkins-Smith HC, Klockow K, Nowlin MC, Silva CL. 2012. "Weather, climate, and worldviews: The sources and consequences of public perceptions of changes in local weather patterns." Weather Clim Soc, 4(2):132-144.

[7] Guilbeault, Douglas, Joshua Becker, and Damon Centola. 2018. "Social learning and partisan bias in the interpretation of climate trends", PNAS, 115(39): 9714-9719.

[8] Hibbing, John R., Kevin B. Smith, John R. Alford. 2014. "Differences in negativity bias underlie variations in political ideology", Behavioral and Brain Sciences, 37, 297-350, doi:10.1017/S0140525X13001192

[9] Howe, Peter D., Jennifer R. Marlon, Matto Mildenberger and Brittany S Shield. 2019. "How will climate change shape climate opinion?", Environmental Research Letters, https://doi.org/10.1088/1748-9326/ab466a. 
[10] Howe PD, Mildenberger M, Marlon JR, Leiserowitz A. 2015. "Geographic variation in opinions on climate change at state and local scales in the USA." Nat Clim Change, $5(6): 596-603$.

[11] Howe PD, Leiseowitz A. 2013. "Who remembers a hot summer or a cold winter? The asymmetric effect of beliefs about global warming on perceptions of local climate conditions in the US." Glob Environ Change, 23(6):1488-1500.

[12] Howe PD, Markowitz EM, Lee TM, Ko C-Y, Leiserowitz A. 2013. "Global perceptions of local temperature change." Nat Clim Chang, 3(4):352-356.

[13] Kaufmann, R. K., M. L Mann, S. Gopal, J. A. Liederman, P.D. Howe, F. Pretis, X. Tang, \& M. Gillmore. 2017. "The Spatial Heterogeneity of Climate Change as an Experiential Basis for Skepticism" Proceedings of the National Academy of Sciences, Vol.114 (1).

[14] Li Y, Johnson EJ, Zaval L. 2011. "Local warming: Daily temperature deviations affect both beliefs and concern about climate change.", Psychol Science, 22(4): 454-459.

[15] Mildenberger, Matto, Peter D. Howe and Chris Miljanich. 2019. "Households with solar installations are ideologically diverse and more politically active than their neighbours", Nature Energy, https://doi.org/10.1038/s41560-019-0498-8.

[16] Weber EU, Stern PC. 2011. "Public understanding of climate change in the United States.", Am Psychol, 66(4): 315-328.

[17] Zaval L, Keenan EA, Johnson EJ, Weber EU. 2014. "How warm days increase belief in global warming.", Nat Clim Change, 4(2):143-147. 


\section{$\underline{\text { Appendix }}$}

Table 1. Number of observations and counties for different values of the TMax index.

\begin{tabular}{lcc}
\hline & \# Obs & \# Counties \\
\hline Strong cooling & 408 & 313 \\
Cooling & 865 & 685 \\
Warming & 2,079 & 1,681 \\
Strong warming & 7,639 & 6,819 \\
\hline
\end{tabular}

Table 2: Perceptions of climate change CCES 2014.

\begin{tabular}{|c|c|c|c|}
\hline & Freq. & Percent & Cum. \\
\hline Global climate change is not occurring; this is not a real issue. & 907 & 9.57 & 9.57 \\
\hline $\begin{array}{l}\text { Concern about global climate change is exaggerated. } \\
\text { No action is necessary. }\end{array}$ & 1,950 & 20.58 & 30.15 \\
\hline $\begin{array}{l}\text { We don't know enough about global climate change, } \\
\text { and more research is necessary before we take any actions. }\end{array}$ & 1,500 & 15.83 & 45.97 \\
\hline $\begin{array}{l}\text { There is enough evidence that climate change is taking place } \\
\text { and some action should be taken. }\end{array}$ & 1,869 & 19.72 & 65.70 \\
\hline $\begin{array}{l}\text { Global climate change has been established as a serious problem, } \\
\text { and immediate action is necessary. }\end{array}$ & 3,251 & 34.30 & 100.00 \\
\hline Total & 9,477 & 100.00 & \\
\hline
\end{tabular}

Table 3: Political ideology CCES 2014.

\begin{tabular}{lccc}
\hline Political Ideology & Freq. & Percent & Cum. \\
\hline Very liberal & 964 & 10.17 & 10.17 \\
Liberal & 1,748 & 18.44 & 28.62 \\
Moderate & 2,961 & 31.24 & 59.86 \\
Conservative & 2,375 & 25.06 & 84.92 \\
Very & & & \\
conservative & 1,429 & 15.08 & 100.00 \\
\hline Total & 9,477 & 100.00 & \\
\hline
\end{tabular}

Table 4: Partisanship CCES 2014.

\begin{tabular}{lccc}
\hline \multicolumn{1}{c}{ Party ID } & Freq. & Percent & Cum. \\
\hline Strong Democrat & 2,558 & 26.99 & 26.99 \\
Not very strong Democrat & 887 & 9.36 & 36.36 \\
Lean Democrat & 878 & 9.27 & 45.62 \\
Independent & 1,172 & 12.37 & 57.99 \\
Lean Republican & 1,258 & 13.28 & 71.26 \\
Not very strong Republican & 888 & 9.37 & 80.64 \\
Strong Republican & 1,835 & 19.36 & 100.00 \\
\hline Total & 9,476 & 100.00 & \\
\hline
\end{tabular}


Figure 1: Perceptions of climate change and partisanship CCES 2014.

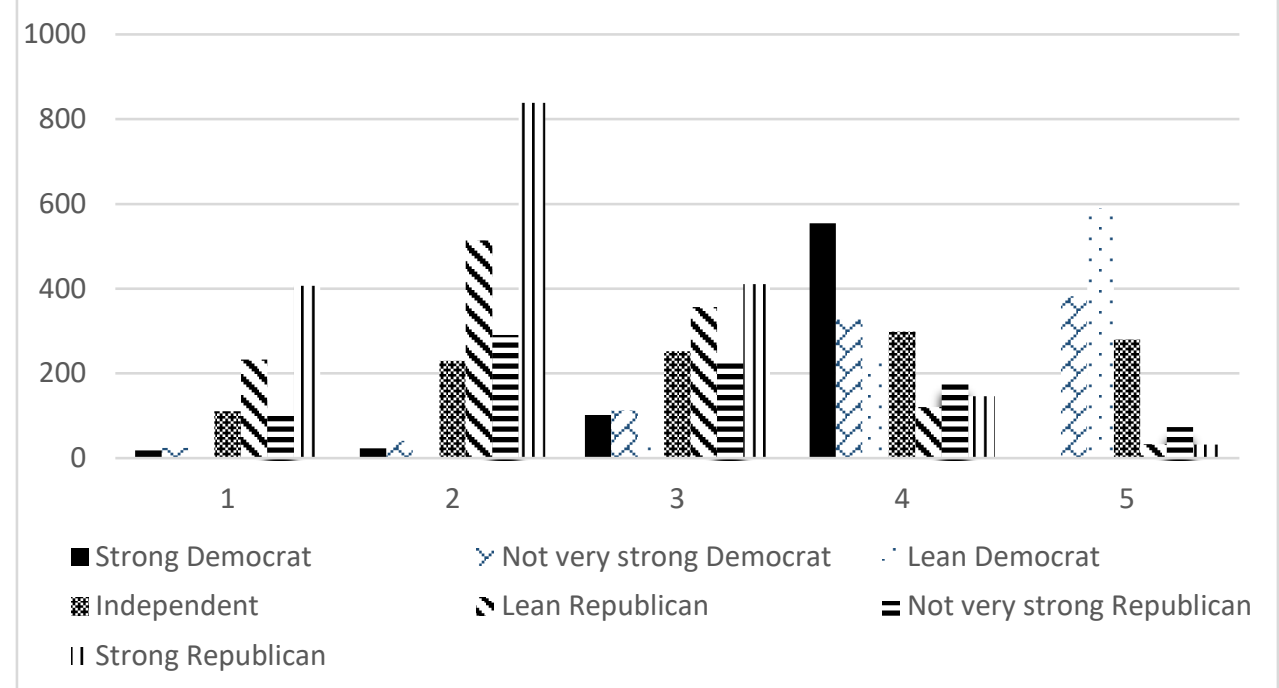

Notes: 1: Global climate change is not occurring; this is not a real issue. 2: Concern about global climate change is exaggerated. No action is necessary. 3: We don't know enough about global climate change, and more research is necessary before we take any actions. 4: There is enough evidence that climate change is taking place and some action should be taken. 5: Global climate change has been established as a serious problem, and immediate action is necessary.

Table 5. Baseline model: determinants of climate change perceptions.

\begin{tabular}{|c|c|c|c|}
\hline & (1) & (2) & (3) \\
\hline \multirow[t]{2}{*}{ TMax } & $0.00242^{* *}$ & $0.000337^{*}$ & $0.0503^{* * *}$ \\
\hline & $(0.000799)$ & $(0.000162)$ & $(0.00421)$ \\
\hline \multirow[t]{2}{*}{ Recent warming in counties that have strongly cooled } & 0.00181 & $0.0519^{* * * *}$ & $0.250^{* * *}$ \\
\hline & $(0.00222)$ & $(0.00131)$ & $(0.0343)$ \\
\hline \multirow[t]{2}{*}{ Recent warming in counties that have cooled } & -0.000604 & $0.0292^{* * *}$ & $0.0499^{* * *}$ \\
\hline & $(0.00172)$ & $(0.000296)$ & $(0.00683)$ \\
\hline \multirow[t]{2}{*}{ Recent cooling in counties that have warmed } & -0.00133 & $0.0109^{* * *}$ & $0.0127^{*}$ \\
\hline & $(0.00148)$ & $(0.000243)$ & $(0.00499)$ \\
\hline \multirow[t]{2}{*}{ Recent cooling in counties that have strongly warmed } & -0.00168 & $0.00446^{* * *}$ & $-0.0170^{* * * *}$ \\
\hline & $(0.00129)$ & $(0.0000626)$ & $(0.00181)$ \\
\hline \multirow[t]{2}{*}{ Very liberal } & & & $0.909^{* * *}$ \\
\hline & & & $(0.0776)$ \\
\hline \multirow[t]{2}{*}{ Liberal } & & & $0.560^{* * *}$ \\
\hline & & & $(0.0470)$ \\
\hline \multirow[t]{2}{*}{ Conservative } & & & $-0.737^{* * *}$ \\
\hline & & & $(0.0468)$ \\
\hline \multirow[t]{2}{*}{ Very conservative } & & & $-1.196^{* * *}$ \\
\hline & & & $(0.0611)$ \\
\hline \multirow[t]{2}{*}{ Strong Democrat } & & & $1.079^{* * * *}$ \\
\hline & & & $(0.0580)$ \\
\hline \multirow[t]{2}{*}{ Not very strong Democrat } & & & $0.568^{* * *}$ \\
\hline & & & $(0.0634)$ \\
\hline \multirow[t]{2}{*}{ Lean Democrat } & & & $1.096^{* * *}$ \\
\hline & & & $(0.0703)$ \\
\hline \multirow[t]{2}{*}{ Lean Republican } & & & $-0.681^{* * *}$ \\
\hline & & & $(0.0614)$ \\
\hline \multirow[t]{2}{*}{ Not very strong Republican } & & & $-0.350^{* * * *}$ \\
\hline & & & $(0.0638)$ \\
\hline \multirow[t]{2}{*}{ Strong Republican } & & & $-0.627^{* * *}$ \\
\hline & & & $(0.0653)$ \\
\hline \multirow[t]{2}{*}{ Gender: Male } & & & $-0.112^{* * * *}$ \\
\hline & & & $(0.0320)$ \\
\hline
\end{tabular}


Race/Ethnicity: Hispanic

Race/Ethnicity: Not White Black or Hispanic

Age: 18-24

$-0.225^{*}$

(0.0618)

0.0223

$(0.356)$

Age: 25-34

Age: 35-44

Age: 55-64

Age: 65 plus

(0.0418)

Education: High School or less

Education: College grad

Education: Post grad

Church attendance: Never

Church attendance: Seldom

Church attendance: A few times a year

Church attendance: Once a week

Church attendance: More than once a week

\section{Cutoff 1}

Cutoff 2

\section{Cutoff 3}

0.397*

No

Yes
(0.980)

No. of Obs

Notes: Ordered probit. Standard errors clustered at the county-level in parenthesis. Dependent variable: "From what you know about global climate change or global warming, which one of the following statements comes closest to your opinion?

1 Global climate change is not occurring; this is not a real issue.

2 Concern about global climate change is exaggerated. No action is necessary.

3 We don't know enough about global climate change,and more research is necessary before we take any actions.

4 There is enough evidence that climate change is taking place and some action should be taken.

5 Global climate change has been established as a serious problem, and immediate action is necessary."

TMax: number of days per year for which the year of the record high temperature is more recent than the year of the record low temperature up to 2010 . Cooling is $163<\mathrm{TMax}<=182$; strong cooling is TMax $<163$; warming is $182<$ TMax $<=201$; strong warming is TMax $>201$. Recent warming (cooling) is defined by the number of the most recent days with record high (low) temperatures since 2005 . 
Table 6. Min and max average marginal effect of TMax and recency weighting from baseline model 3.

\begin{tabular}{ccccccccc} 
& \multicolumn{2}{c}{ Outcome 1 } & \multicolumn{2}{c}{ Outcome 2 } & \multicolumn{2}{c}{ Outcome 4 } & \multicolumn{2}{c}{ Outcome 5 } \\
\hline & Min & Max & Min & Max & Min & Max & Min & Max \\
\hline TMax & $-0,50$ & 0,69 & $-0,35$ & 0,48 & $-0,05$ & 0,03 & $-1,13$ & 0,82 \\
RW 1 & $-1,96$ & $-0,06$ & $-1,37$ & $-0,04$ & 0,00 & 0,13 & 0,10 & 3,19 \\
RW 2 & $-0,50$ & $-0,02$ & $-0,35$ & $-0,02$ & 0,00 & 0,03 & 0,04 & 0,82 \\
RW 3 & $-0,12$ & 0,00 & $-0,08$ & 0,00 & 0,00 & 0,01 & 0,00 & 0,19 \\
RW 4 & $-0,03$ & 0,13 & $-0,02$ & 0,09 & $-0,01$ & 0,00 & $-0,22$ & 0,04 \\
\hline
\end{tabular}

Notes: min and max average marginal effect of TMax and recency weighting from Model 3

Baseline. Outcome 1: Global climate change is not occurring; this is not a real issue. Outcome 2:

Concern about global climate change is exaggerated. No action is necessary. Outcome 4: There is enough evidence that climate change is taking place and some action should be taken. Outcome 5:

Global climate change has been established as a serious problem, and immediate action is necessary.

Table 7. Baseline model 3 with heterogeneous effects by party identification and political ideology.

\begin{tabular}{lc}
\hline & $(3)$ \\
\hline TMax & $0.0581^{* * *}$ \\
Recent warming in counties that have strongly cooled & $(0.00512)$ \\
& $0.312^{* * *}$ \\
Recent warming in counties that have cooled & $(0.0422)$ \\
& $0.0636^{* * *}$ \\
Recent cooling in counties that have warmed & $(0.00831)$ \\
& $0.0222^{* * *}$ \\
Recent cooling in counties that have strongly warmed & $(0.00614)$ \\
& $-0.0137^{* * *}$ \\
Very liberal & $(0.00210)$ \\
& 0.961 \\
Liberal & $(0.554)$ \\
Conservative & $0.756^{*}$ \\
Very conservative & $(0.320)$ \\
Strong Democrat & 0.424 \\
& $(0.373)$ \\
Not very strong Democrat & $-0.946^{*}$ \\
Lean Democrat & $(0.429)$ \\
Lean Republican & $0.826^{*}$ \\
Not very strong Republican & $(0.405)$ \\
Strong Republican & 0.431 \\
Strong Democrat*TMax & $(0.427)$ \\
Not very strong Democrat*TMax & $1.329^{* *}$ \\
Lean Democrat*TMax & $(0.513)$ \\
& $-0.944^{*}$ \\
& $(0.410)$ \\
& $-0.905^{*}$ \\
& $(0.401)$ \\
& $-0.988^{*}$ \\
& $(0.479)$ \\
& 0.00116 \\
& $(0.00178)$ \\
& 0.000614 \\
& $(0.00192)$ \\
& -0.00103 \\
& $(0.00226)$ \\
& \\
& \\
&
\end{tabular}


Lean Republican*TMax

0.00120

$(0.00187)$

Not very strong Republican*TMax

0.00253

$(0.00181)$

Strong Republican*TMax

0.00166

$(0.00221)$

Very liberal*TMax

$-0.000240$

$(0.00251)$

Liberal*TMax

$-0.000891$

(0.00140)

Conservative*TMax

$-0.00530^{* *}$

$(0.00172)$

Very conservative*TMax

$-0.00114$

Gender: Male

$(0.00194)$

$-0.113^{* * * *}$

(0.0320)

Race/Ethnicity: Black

$-0.294^{* * *}$

(0.0737)

Race/Ethnicity: Hispanic

0.0461

$(0.0783)$

Race/Ethnicity: Not White Black or Hispanic

$-0.234^{* * *}$

$(0.0619)$

0.0302

Age: $18-24$

$(0.356)$

Age: 25-34

0.175

$(0.0991)$

0.0566

(0.0696)

0.0613

Age: 55-64

(0.0419)

Age: 65 plus

$0.120^{* *}$

$(0.0415)$

$-0.0624$

$(0.0432)$

$0.104^{* *}$

(0.0382)

$0.226^{* * *}$

(0.0471)

$0.145^{*}$

(0.0619)

0.0272

(0.0637)

$-0.0334$

(0.0643)

$-0.0884$

(0.0629)

$-0.0773$

(0.0692)

$9.482^{* * * *}$

Cutoff 1

(1.191)

$10.77^{* * * *}$

(1.191)

$11.65^{\text {**** }}$

(1.193)

$12.76^{\text {**** }}$

Cutoff 4 
Source: CCES 2014. ${ }^{*} p<0.05,{ }^{* * *} p<0.01,{ }^{* * * *} p<0.001$.

Notes: Ordered probit. Standard errors clustered at the county-level in parenthesis. 
$\underline{\text { Additional Tables and Figures (Online Appendix) }}$

Table 8. Main descriptive statistics CCES 2014.

\begin{tabular}{lllcc} 
& mean & sd & min & max \\
\hline Ideology & 3.164 & 1.190 & 1 & 5 \\
PID & 3.812 & 2.260 & 1 & 7 \\
Gender & 0.555 & 0.497 & 0 & 1 \\
Race & 1.304 & 0.779 & 1 & 4 \\
Age & 5.079 & 1.059 & 1 & 6 \\
Education & 2.398 & 0.990 & 1 & 4 \\
Attend & 2.911 & 1.745 & 1 & 6 \\
---------- & \\
N & 10993 & & & \\
-
\end{tabular}

Figure 2: Average marginal effects by value of the dependent variable from Baseline Model 3.

5: Global climate change has been established as a serious problem, and immediate action is necessary.

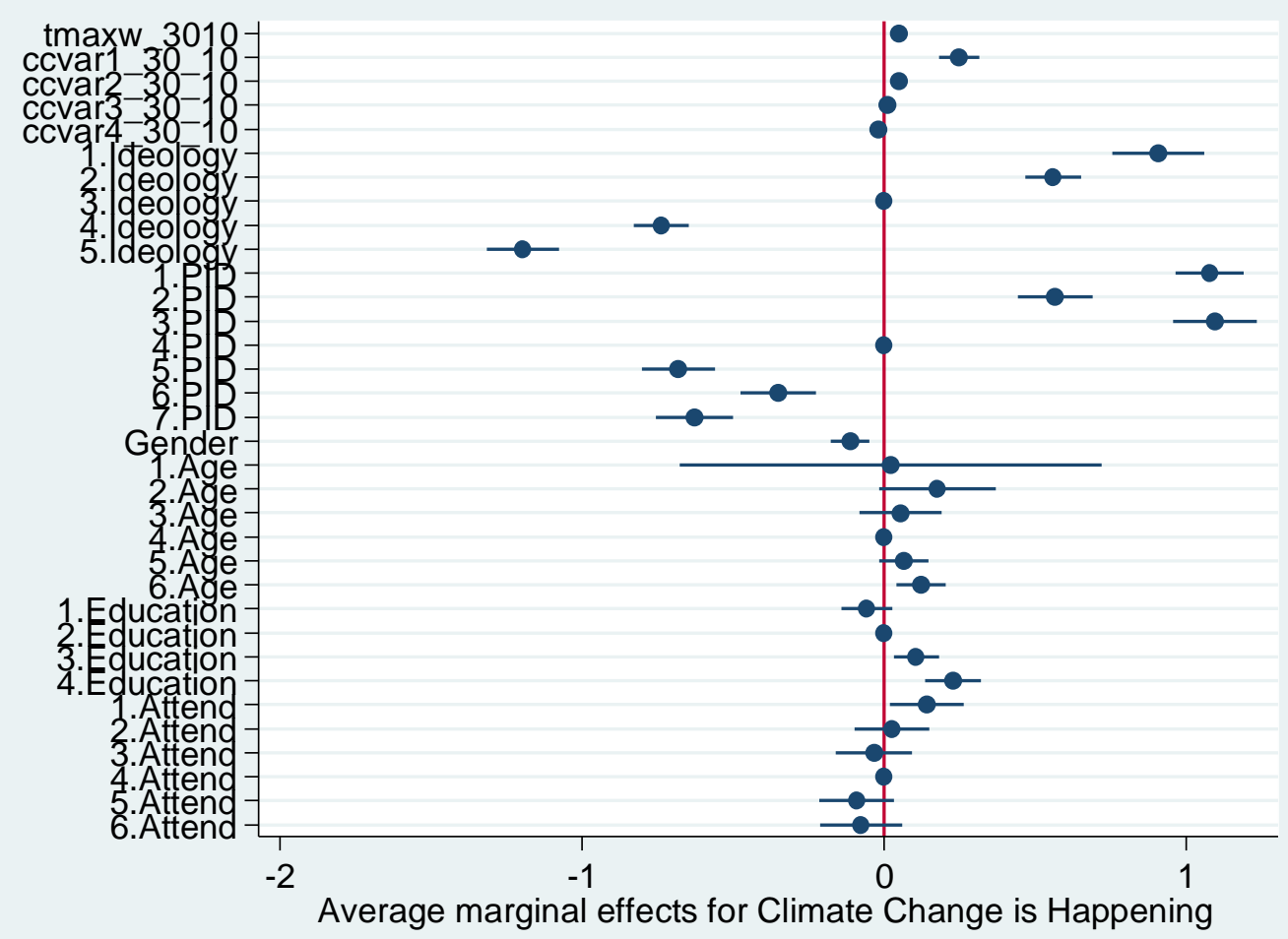


4: There is enough evidence that climate change is taking place and some action should be taken.

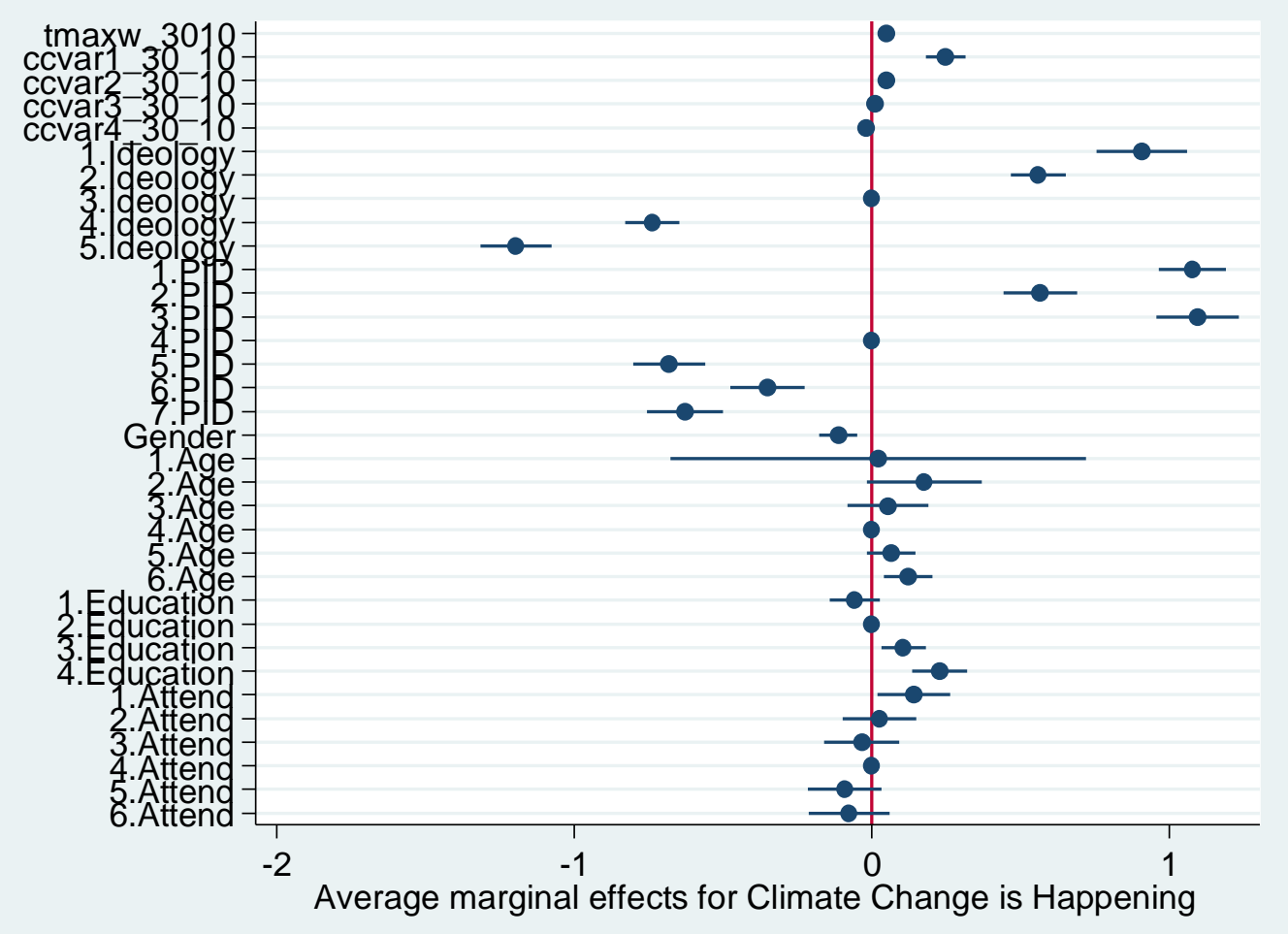

3: We don't know enough about global climate change and more research is necessary before we take any actions.

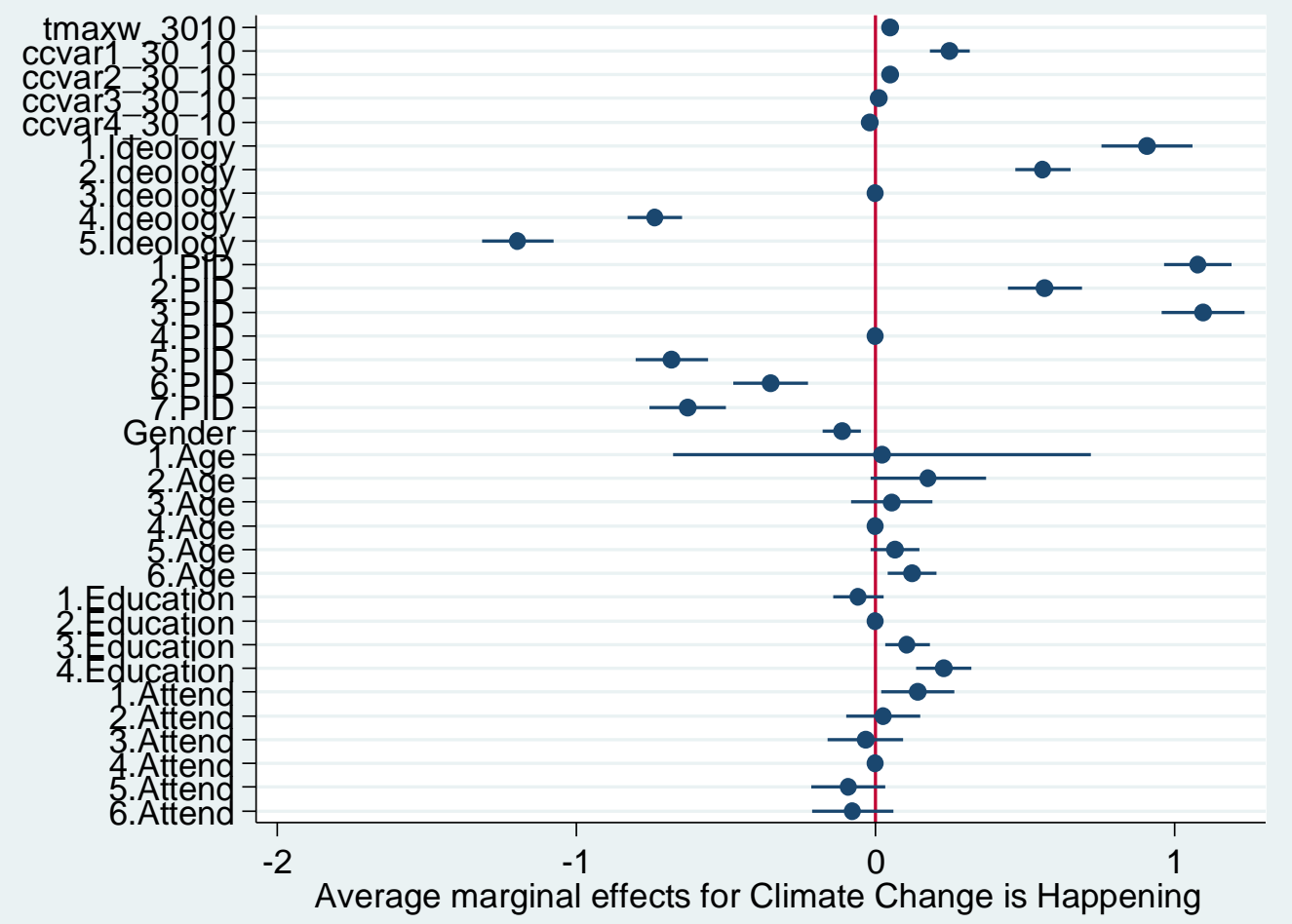


2: Concern about global climate change is exaggerated. No action is necessary.

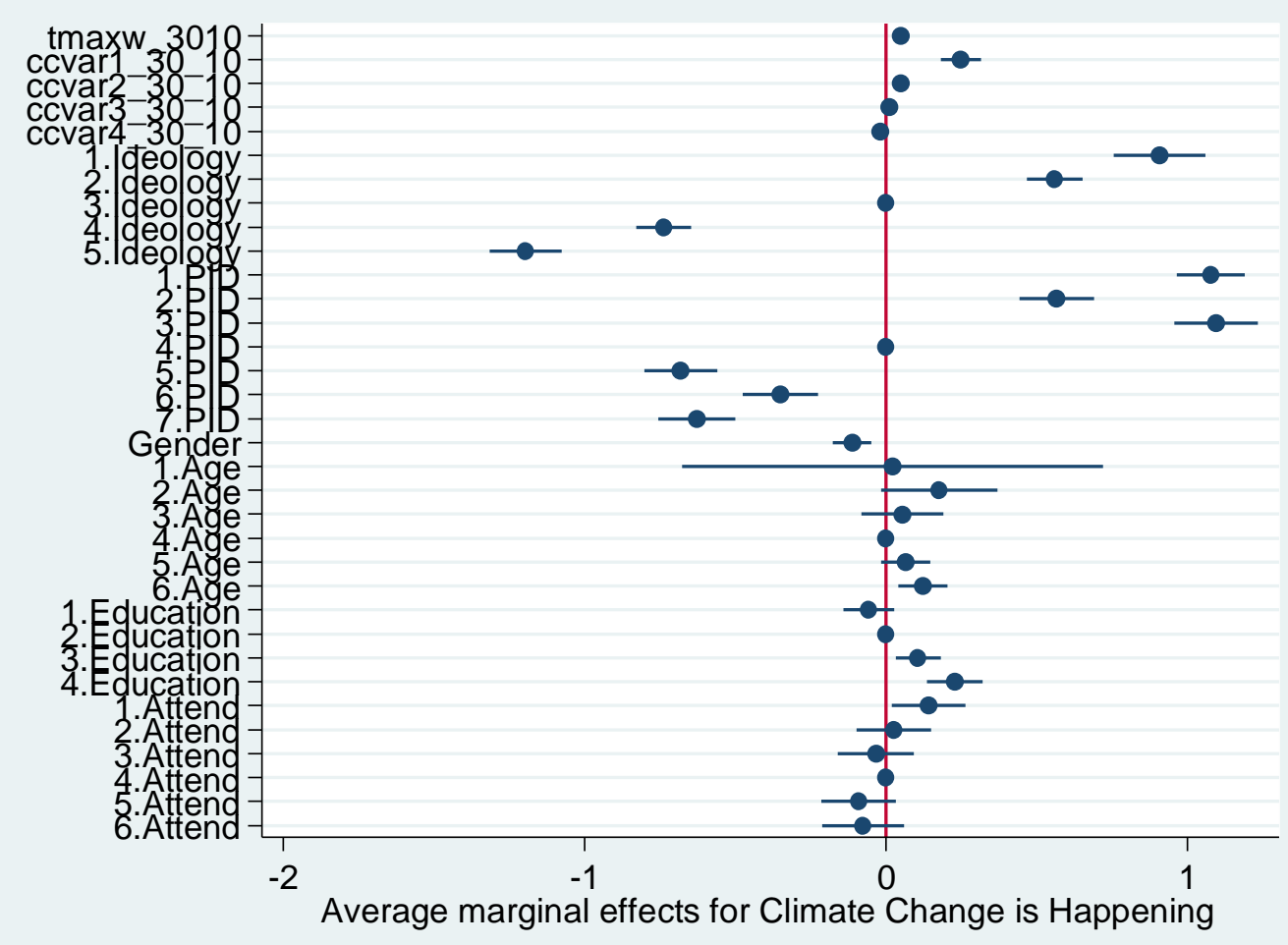

1: Global climate change is not occurring; this is not a real issue.

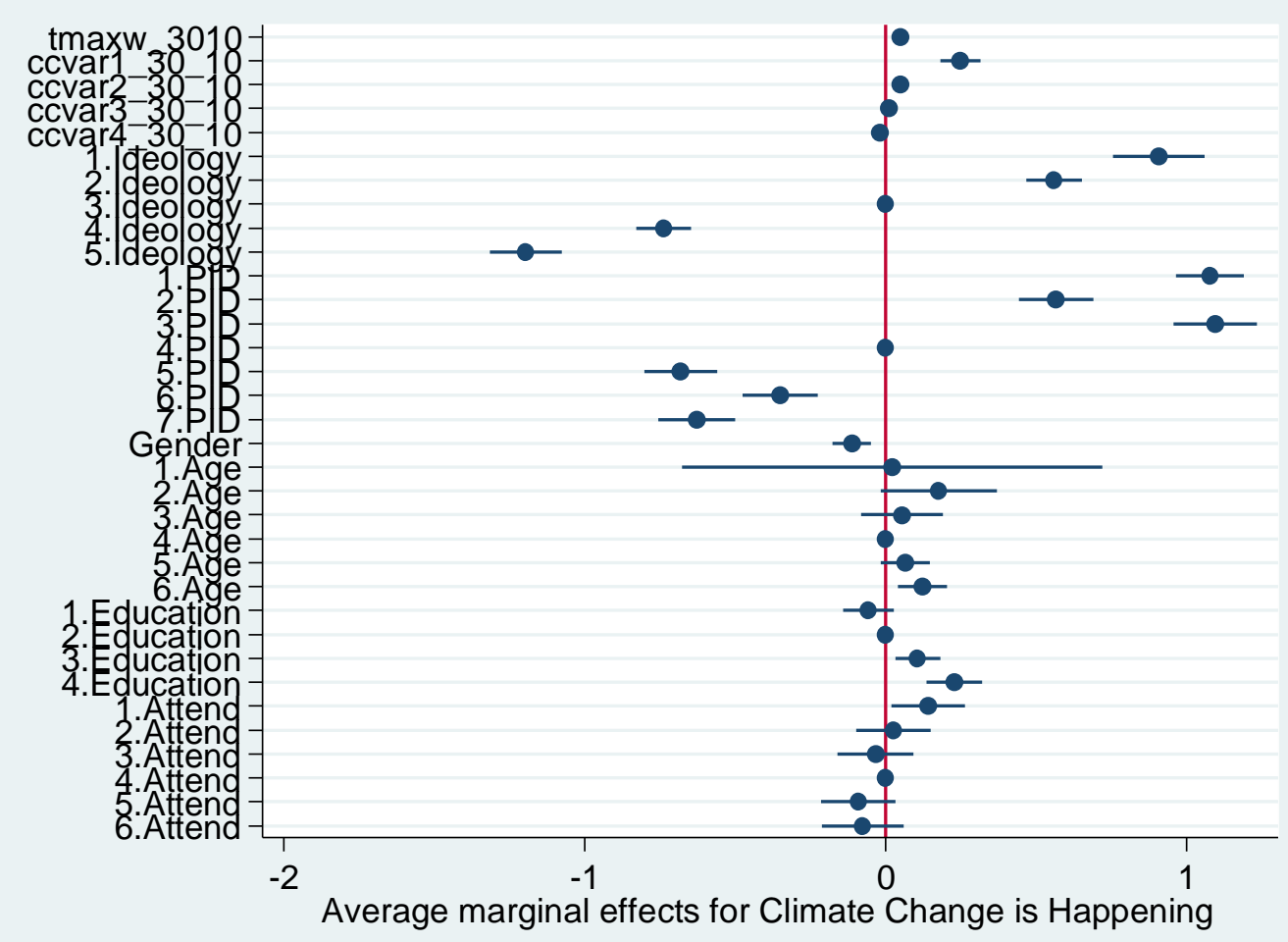


Figure 3: County distribution of average marginal effects of climate indexes from Baseline Model 3 for outcome 5 "Global climate change has been established as a serious problem, and immediate action is necessary".
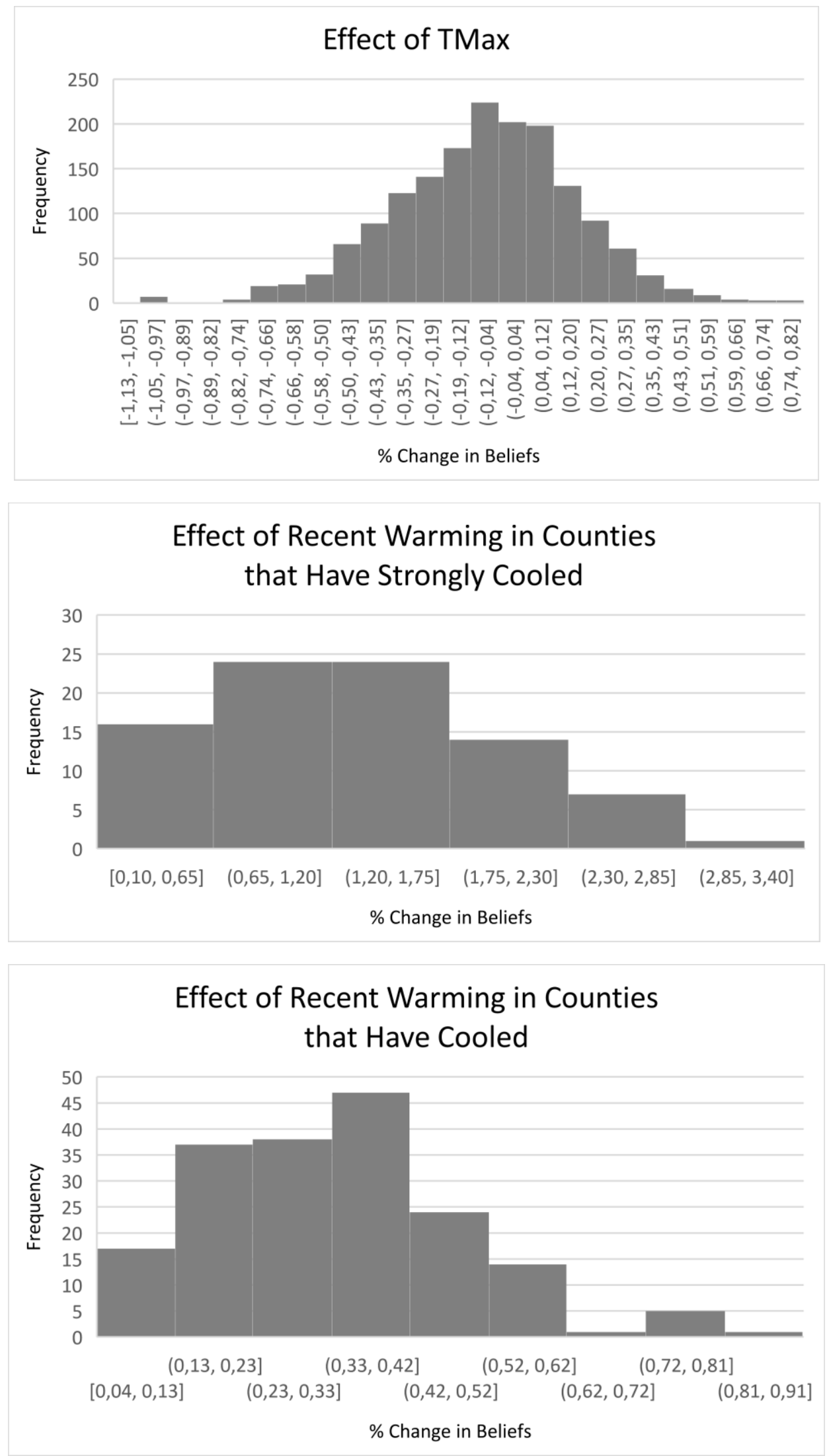

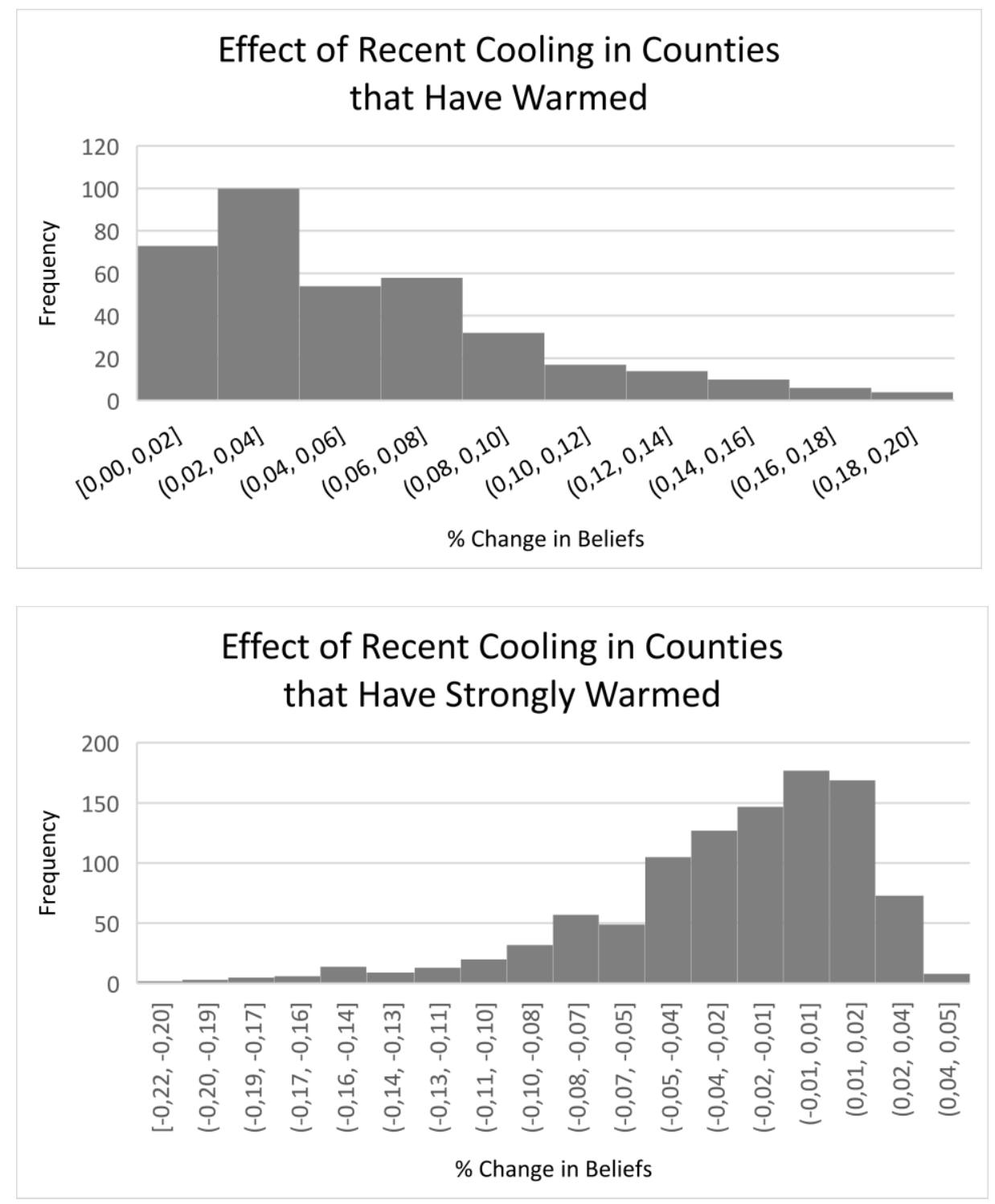

Table 9: Determinants of climate change perceptions.

30 years TMax time series by number of maximum missing values.

\begin{tabular}{lccc}
\hline & 5 missing & 10 missing & 15 missing \\
\hline TMax & $0.0482^{* * * *}$ & $0.0503^{* * * *}$ & $0.115^{* * * *}$ \\
Recent warming in counties that have strongly cooled & $(0.00380)$ & $(0.00421)$ & $(0.00759)$ \\
& $\left(0.0184^{* *}\right.$ & $0.250^{* * * *}$ & $0.314^{* * * *}$ \\
Recent warming in counties that have cooled & 0.00179 & $(0.0343)$ & $(0.0255)$ \\
& $(0.00535)$ & $\left(0.0499^{* * *}\right.$ & $0.317^{* * *}$ \\
Recent cooling in counties that have warmed & -0.00212 & $0.0127^{*}$ & $(0.0254)$ \\
& $(0.00399)$ & $(0.00499)$ & $\left(0.0596^{* * *}\right.$ \\
Recent cooling in counties that have strongly warmed & $-0.0443^{* * * *}$ & $-0.0170^{* * * *}$ & $0.0638^{* * *}$ \\
Very liberal & $(0.00246)$ & $(0.00181)$ & $(0.00877)$ \\
& $0.909^{* * *}$ & $0.909^{* * * *}$ & $0.909^{* * *}$ \\
Liberal & $(0.0776)$ & $(0.0776)$ & $(0.0776)$ \\
Conservative & $0.560^{* * *}$ & $0.560^{* * * *}$ & $0.560^{* * *}$ \\
& $(0.0470)$ & $(0.0470)$ & $(0.0470)$ \\
Very conservative & $-0.737^{* * *}$ & $-0.737^{* * *}$ & $-0.737^{* * *}$ \\
& $(0.0468)$ & $(0.0468)$ & $(0.0468)$
\end{tabular}


Strong Democrat

Not very strong Democrat

Lean Democrat

Lean Republican

Not very strong Republican

Strong Republican

Gender: Male

Race/Ethnicity: Black

Race/Ethnicity: Hispanic

Race/Ethnicity: Not White Black or Hispanic

Age: $18-24$

Age: $25-34$

Age: $35-44$

Age: 55-64

Age: 65 plus

Education: High School or less

Education: College grad

Education: Post grad

Church attendance: Never

Church attendance: Seldom

Church attendance: A few times a year

Church attendance: Once a week

Church attendance: More than once a week

Cutoff 1

Cutoff 2

Cutoff 3

Cutoff 4

\begin{tabular}{|c|c|c|}
\hline$(0.0611)$ & $(0.0611)$ & $(0.0611)$ \\
\hline $1.079^{* * * *}$ & $1.079^{* * *}$ & $1.079^{* * *}$ \\
\hline$(0.0580)$ & $(0.0580)$ & $(0.0580)$ \\
\hline $0.568^{* * *}$ & $0.568^{* * *}$ & $0.568^{* * * *}$ \\
\hline$(0.0634)$ & $(0.0634)$ & $(0.0634)$ \\
\hline $1.096^{* * *}$ & $1.096^{* * *}$ & $1.096^{* * * *}$ \\
\hline$(0.0703)$ & $(0.0703)$ & $(0.0703)$ \\
\hline$-0.681^{\text {**** }}$ & $-0.681^{* * *}$ & $-0.681^{* * * *}$ \\
\hline$(0.0614)$ & $(0.0614)$ & $(0.0614)$ \\
\hline$-0.350^{* * * *}$ & $-0.350^{* * * *}$ & $-0.350^{* * * *}$ \\
\hline$(0.0638)$ & $(0.0638)$ & $(0.0638)$ \\
\hline$-0.627^{* * * *}$ & $-0.627^{* * * *}$ & $-0.627^{* * * *}$ \\
\hline$(0.0653)$ & $(0.0653)$ & $(0.0653)$ \\
\hline$-0.112^{* * *}$ & $-0.112^{* * *}$ & $-0.112^{* * *}$ \\
\hline$(0.0320)$ & $(0.0320)$ & $(0.0320)$ \\
\hline$-0.292^{* * *}$ & $-0.292^{* * *}$ & $-0.292^{* * *}$ \\
\hline$(0.0733)$ & $(0.0733)$ & $(0.0733)$ \\
\hline 0.0391 & 0.0391 & 0.0391 \\
\hline$(0.0786)$ & $(0.0786)$ & $(0.0786)$ \\
\hline$-0.225^{* * *}$ & $-0.225^{* * *}$ & $-0.225^{* * *}$ \\
\hline$(0.0618)$ & $(0.0618)$ & $(0.0618)$ \\
\hline 0.0223 & 0.0223 & 0.0223 \\
\hline$(0.356)$ & $(0.356)$ & $(0.356)$ \\
\hline 0.177 & 0.177 & 0.177 \\
\hline$(0.0984)$ & $(0.0984)$ & $(0.0984)$ \\
\hline 0.0558 & 0.0558 & 0.0558 \\
\hline$(0.0692)$ & $(0.0692)$ & $(0.0692)$ \\
\hline 0.0657 & 0.0657 & 0.0657 \\
\hline$(0.0418)$ & $(0.0418)$ & $(0.0418)$ \\
\hline $0.123^{* *}$ & $0.123^{* *}$ & $0.123^{* *}$ \\
\hline$(0.0416)$ & $(0.0416)$ & $(0.0416)$ \\
\hline-0.0568 & -0.0568 & -0.0568 \\
\hline$(0.0429)$ & $(0.0429)$ & $(0.0429)$ \\
\hline $0.108^{* *}$ & $0.108^{* * *}$ & $0.108^{* *}$ \\
\hline$(0.0382)$ & $(0.0382)$ & $(0.0382)$ \\
\hline $0.229^{* * *}$ & $0.229^{* * *}$ & $0.229^{* * *}$ \\
\hline$(0.0473)$ & $(0.0473)$ & $(0.0473)$ \\
\hline $0.142^{*}$ & $0.142^{*}$ & $0.142^{*}$ \\
\hline$(0.0620)$ & $(0.0620)$ & $(0.0620)$ \\
\hline 0.0267 & 0.0267 & 0.0267 \\
\hline$(0.0634)$ & $(0.0634)$ & $(0.0634)$ \\
\hline-0.0330 & -0.0330 & -0.0330 \\
\hline$(0.0644)$ & $(0.0644)$ & $(0.0644)$ \\
\hline-0.0900 & -0.0900 & -0.0900 \\
\hline$(0.0629)$ & $(0.0629)$ & $(0.0629)$ \\
\hline-0.0763 & -0.0763 & -0.0763 \\
\hline$(0.0692)$ & $(0.0692)$ & $(0.0692)$ \\
\hline $6.190^{* * *}$ & $7.597^{* * * *}$ & $24.40^{* * *}$ \\
\hline$(0.840)$ & $(0.973)$ & $(1.890)$ \\
\hline $7.473^{* * * *}$ & $8.880^{* * * *}$ & $25.68^{* * * *}$ \\
\hline$(0.847)$ & $(0.975)$ & (1.896) \\
\hline $8.359^{* * * *}$ & $9.767^{* * * *}$ & $26.57^{* * * *}$ \\
\hline$(0.847)$ & $(0.977)$ & (1.902) \\
\hline $9.459^{* * *}$ & $10.87^{* * *}$ & $27.66^{* * *}$ \\
\hline$(0.849)$ & $(0.980)$ & (1.904) \\
\hline 9407 & 9407 & 9407 \\
\hline
\end{tabular}


Source: CCES 2014. ${ }^{*} p<0.05,{ }^{* *} p<0.01,{ }^{* * *} p<0.001$. Standard errors clustered at the county-level in parenthesis.

Table 10: Determinants of climate change perceptions.

Max 10 missing values by length of TMax time series: 30,40 and 50 years.

\begin{tabular}{|c|c|c|c|}
\hline & 30 years & 40 years & 50 years \\
\hline TMax & $\begin{array}{l}0.0503^{* * *} \\
(0.00421)\end{array}$ & $\begin{array}{l}0.0558^{* * *} \\
(0.00902)\end{array}$ & $\begin{array}{l}0.0305^{* * *} \\
(0.00219)\end{array}$ \\
\hline Recent warming in counties that have strongly cooled & $\begin{array}{l}0.250^{* * *} \\
(0.0343)\end{array}$ & $\begin{array}{l}0.676^{* * *} \\
(0.0912)\end{array}$ & $\begin{array}{l}0.390^{* * *} \\
(0.0203)\end{array}$ \\
\hline Recent warming in counties that have cooled & $\begin{array}{l}0.0499^{* * * *} \\
(0.00683)\end{array}$ & $\begin{array}{l}0.0518^{* *} \\
(0.0196)\end{array}$ & $\begin{array}{l}-0.0151^{* * *} \\
(0.00256)\end{array}$ \\
\hline Recent cooling in counties that have warmed & $\begin{array}{c}0.0127^{*} \\
(0.00499)\end{array}$ & $\begin{array}{l}0.0368^{* *} \\
(0.0143)\end{array}$ & $\begin{array}{l}-0.0122^{* * *} \\
(0.00249)\end{array}$ \\
\hline Recent cooling in counties that have strongly warmed & $\begin{array}{c}-0.0170^{* * *} \\
(0.00181)\end{array}$ & $\begin{array}{c}0.0159 \\
(0.0140)\end{array}$ & $\begin{array}{l}-0.0330^{* * *} \\
(0.00164)\end{array}$ \\
\hline Very liberal & $\begin{array}{l}0.909^{* * *} \\
(0.0776)\end{array}$ & $\begin{array}{l}0.910^{* * * *} \\
(0.0776)\end{array}$ & $\begin{array}{l}0.910^{* * *} \\
(0.0776)\end{array}$ \\
\hline Liberal & $\begin{array}{l}0.560^{* * * *} \\
(0.0470)\end{array}$ & $\begin{array}{l}0.560^{* * * *} \\
(0.0470)\end{array}$ & $\begin{array}{l}0.560^{* * * *} \\
(0.0470)\end{array}$ \\
\hline Conservative & $\begin{array}{l}-0.737^{* * *} \\
(0.0468)\end{array}$ & $\begin{array}{l}-0.738^{* * * *} \\
(0.0468)\end{array}$ & $\begin{array}{c}-0.738^{* * * *} \\
(0.0468)\end{array}$ \\
\hline Very conservative & $\begin{array}{c}-1.196^{* * *} \\
(0.0611)\end{array}$ & $\begin{array}{l}-1.196^{* * * *} \\
(0.0611)\end{array}$ & $\begin{array}{l}-1.196^{* * * *} \\
(0.0611)\end{array}$ \\
\hline Strong Democrat & $\begin{array}{l}1.079^{* * * *} \\
(0.0580)\end{array}$ & $\begin{array}{l}1.081^{* * * *} \\
(0.0580)\end{array}$ & $\begin{array}{l}1.081^{* * * *} \\
(0.0580)\end{array}$ \\
\hline Not very strong Democrat & $\begin{array}{l}0.568^{* * * *} \\
(0.0634)\end{array}$ & $\begin{array}{l}0.569^{* * * *} \\
(0.0634)\end{array}$ & $\begin{array}{l}0.569^{* * * *} \\
(0.0634)\end{array}$ \\
\hline Lean Democrat & $\begin{array}{l}1.096^{* * * *} \\
(0.0703)\end{array}$ & $\begin{array}{l}1.098^{* * * *} \\
(0.0703)\end{array}$ & $\begin{array}{l}1.098^{* * * *} \\
(0.0703)\end{array}$ \\
\hline Lean Republican & $\begin{array}{c}-0.681^{* * *} \\
(0.0614)\end{array}$ & $\begin{array}{l}-0.680^{* * * *} \\
(0.0614)\end{array}$ & $\begin{array}{c}-0.680^{* * * *} \\
(0.0614)\end{array}$ \\
\hline Not very strong Republican & $\begin{array}{c}-0.350^{* * *} \\
(0.0638)\end{array}$ & $\begin{array}{l}-0.349^{* * * *} \\
(0.0638)\end{array}$ & $\begin{array}{c}-0.349^{\text {***** }} \\
(0.0638)\end{array}$ \\
\hline Strong Republican & $\begin{array}{l}-0.627^{* * * *} \\
(0.0653)\end{array}$ & $\begin{array}{l}-0.626^{* * *} \\
(0.0653)\end{array}$ & $\begin{array}{l}-0.626^{* * *} \\
(0.0653)\end{array}$ \\
\hline Gender: Male & $\begin{array}{l}-0.112^{* * *} \\
(0.0320)\end{array}$ & $\begin{array}{l}-0.112^{* * *} \\
(0.0320)\end{array}$ & $\begin{array}{l}-0.112^{* * *} \\
(0.0320)\end{array}$ \\
\hline Race/Ethnicity: Black & $\begin{array}{l}-0.292^{* * * *} \\
(0.0733)\end{array}$ & $\begin{array}{l}-0.292^{* * * *} \\
(0.0733)\end{array}$ & $\begin{array}{l}-0.292^{* * * *} \\
(0.0733)\end{array}$ \\
\hline Race/Ethnicity: Hispanic & $\begin{array}{c}0.0391 \\
(0.0786)\end{array}$ & $\begin{array}{c}0.0392 \\
(0.0787)\end{array}$ & $\begin{array}{c}0.0392 \\
(0.0787)\end{array}$ \\
\hline Race/Ethnicity: Not White Black or Hispanic & $\begin{array}{l}-0.225^{* * *} \\
(0.0618)\end{array}$ & $\begin{array}{l}-0.225^{* * * *} \\
(0.0618)\end{array}$ & $\begin{array}{l}-0.225^{* * * *} \\
(0.0618)\end{array}$ \\
\hline Age: $18-24$ & $\begin{array}{l}0.0223 \\
(0.356)\end{array}$ & $\begin{array}{l}0.0217 \\
(0.356)\end{array}$ & $\begin{array}{l}0.0217 \\
(0.356)\end{array}$ \\
\hline Age: $25-34$ & $\begin{array}{c}0.177 \\
(0.0984)\end{array}$ & $\begin{array}{c}0.177 \\
(0.0984)\end{array}$ & $\begin{array}{c}0.177 \\
(0.0984)\end{array}$ \\
\hline Age: $35-44$ & $\begin{array}{c}0.0558 \\
(0.0692)\end{array}$ & $\begin{array}{c}0.0557 \\
(0.0692)\end{array}$ & $\begin{array}{c}0.0557 \\
(0.0692)\end{array}$ \\
\hline Age: $55-64$ & $\begin{array}{c}0.0657 \\
(0.0418)\end{array}$ & $\begin{array}{c}0.0655 \\
(0.0418)\end{array}$ & $\begin{array}{c}0.0655 \\
(0.0418)\end{array}$ \\
\hline Age: 65 plus & $\begin{array}{c}0.123^{* *} \\
(0.0416)\end{array}$ & $\begin{array}{c}0.123^{* *} \\
(0.0416)\end{array}$ & $\begin{array}{c}0.123^{* *} \\
(0.0416)\end{array}$ \\
\hline Education: High School or less & $\begin{array}{c}-0.0568 \\
(0.0429)\end{array}$ & $\begin{array}{l}-0.0569 \\
(0.0429)\end{array}$ & $\begin{array}{l}-0.0569 \\
(0.0429)\end{array}$ \\
\hline Education: College grad & $0.108^{* *}$ & $0.108^{* * *}$ & $0.108^{* *}$ \\
\hline
\end{tabular}


Education: Post grad

Church attendance: Never

Church attendance: Seldom

Church attendance: A few times a year

Church attendance: Once a week

Church attendance: More than once a week

Cutoff 1

Cutoff 2

Cutoff 3

Cutoff 4

$\begin{array}{ccc}(0.0382) & (0.0382) & (0.0382) \\ 0.229^{* * *} & 0.228^{* * *} & 0.228^{* * *} \\ (0.0473) & (0.0472) & (0.0472) \\ 0.142^{*} & 0.143^{*} & 0.143^{*} \\ (0.0620) & (0.0620) & (0.0620) \\ 0.0267 & 0.0272 & 0.0272 \\ (0.0634) & (0.0634) & (0.0634) \\ -0.0330 & -0.0330 & -0.0330 \\ (0.0644) & (0.0644) & (0.0644) \\ -0.0900 & -0.0908 & -0.0908 \\ (0.0629) & (0.0629) & (0.0629) \\ -0.0763 & -0.0764 & -0.0764 \\ (0.0692) & (0.0692) & (0.0692) \\ 7.597^{* * *} & 9.952^{* * * *} & 2.523^{* * *} \\ (0.973) & (2.440) & (0.458) \\ 8.880^{* * *} & 11.24^{* * * *} & 3.807^{* * *} \\ (0.975) & (2.447) & (0.463) \\ 9.767^{* * *} & 12.12^{* * * *} & 4.694^{* * *} \\ (0.977) & (2.452) & (0.467) \\ 10.87^{* * *} & 13.22^{* * *} & 5.793^{* * *} \\ (0.980) & (2.453) & (0.470)\end{array}$

9415

No. of Obs $\quad$ Source: CCES 2014. ${ }^{*} p<0.05,{ }^{* *} p<0.01,{ }^{* * *} p<0.001$. Standard errors clustered at the county-level in parenthesis.

No. of Obs $\quad$ Source: CCES 2014. ${ }^{*} p<0.05,{ }^{* *} p<0.01,{ }^{* * *} p<0.001$. Standard errors clustered at the county-level in parenthesis. 